\title{
RETROSPECTIVE STUDY ON CONGENITAL AND ACQUIRED FISTULAE IN SOME FARM ANIMALS AND THEIR MANAGEMENT IN THE FIELD
}

\author{
MISK T.N. ${ }^{1}$ AND MISK N.A. ${ }^{2}$ \\ ${ }^{1}$ Department of Surgery, Faculty of Veterinary Medicine, Sadat City University, Sadat City, Menofia, Egypt. \\ ${ }^{2}$ Department of Surgery, Anaesthiology and Radiology, Faculty of Veterinary Medicine, Assiut University, Assiut, Egypt.
}

Received: 30 December 2019; Accepted: 16 January 2020

\begin{abstract}
The aim of the present study is to record the common congenital and acquired fistulae in some farm animals and to throw a light on the treatment regimes which can be satisfactory to correct the fistulae in field situation. The present study was carried out on 129 animals registered during field trips to villages of 27 provinces allover Egypt form 2003 - 2018. Animals were cattle $(n=43)$, buffaloes $(n=38)$, sheep $(n=20)$, goats $(n=11)$, camels $(n=3)$, donkeys $(n=7)$ and horses $(n=7) .6$ types of congenital and acquired fistulae were recorded in farm animals namely; recto-vaginal $(n=58)$, urethral $(n=31)$, teat $(n=14)$, salivary $(n=14)$, oral $(n=9)$ and perianal $(n=3)$. Diagnosis was based on case history and clinical examination conducted in the field. Surgical treatment was performed using routine maneuvers reported in literature and textbooks. Results indicated that surgical intervention is the only possible solution for treatment of more than $83 \%$ of all registered congenital and acquired fistulae to satisfy the requirements of the owners and make the affected animals more profitable to national income.
\end{abstract}

Keywords: Fistulae, farm animals.

\section{INTRODUCTION}

Several varieties of congenital and acquired fistulae are recorded in different farm animals. They include, salivary, oronasal, cleft-palate, oral, tracheal, esophageal, trachea-esophageal, ruminal, intestinal, urethral, teat, recto-vaginal and urachal fistulae (Dyne et al., 1964; Ellison, 1995; Michael, 1995; Smith, 2001; Zopa et al., 2008; Misk et al., 2013; Shannon et al., 2013; Misk et al., 2014; Singh et al., 2016; Ogawa et al., 2017; Perego et al., 2017; Khan et al., 2018; Misk et al., 2018, Sato et al., 2019 and Yi Gao et al., 2019).

Congenital defects present at birth may be caused by genetic or environmental factors or combination of both. Congenital anomalies have been estimated to occur in $0.2 \%-5 \%$ of calves. They may lead to perinatal mortality and may also decrease maternal productivity and reduce the value of the neonates (Ghanem et al., 2004; Ghanem et al., 2005; Bademkirin et al., 2006 and Magda et al., 2007). Acquired fistulae usually occur as a result of injury or trauma to the animal (Bademkiran et al., 2009 and Shakoor et al., 2011).

Corresponding author: Dr. MISK TN.

E-mail address: tarik.misk@vet.usc.edu.eg

Present address: Department of Surgery, Anesthesiology and Radiology, Faculty of Veterinary Medicine, Sadat City University, Sadat City, Menofia, Egypt.
The fate of treatment of either congenital or acquired fistula is controversial and subjected to several factors including the species of the animal, the seat and type of fistulae and time elapsed etc.

The aim of the present study is to record the common congenital and/or acquired fistulae in some farm animals and to throw a light on the surgical treatment regimes which can be satisfactory to correct the fistulae in field situation.

\section{MATERIALS AND METHODS}

The present study was carried out on 129 animals suffering from different types of fistulae registered during field trips to villages of 27 provinces allover Egypt from 2003 to 2018.

Animals were cattle (Holstein - friesians and local breeds) $(n=43)$, water buffaloes (Bubalus bubalis) $(\mathrm{n}=38)$, sheep (Rahmany - Barki - Local breeds) ( $=20)$ goats (Baladi - Zarabi) $(\mathrm{n}=11)$, camels (Camelus dromedarius) $(\mathrm{n}=3)$, donkeys (local breeds) $(n=7)$ and horses (mixed breeds) $(n=7)$.

In the present study 6 types of congenital and acquired fistulae were recorded in farm animals namely; recto-vaginal $(\mathrm{n}=58)$, urethral $(\mathrm{n}=31)$, teat $(n=14)$, salivary $(n=14)$, oral $(n=9)$ and perianal $(n=3)$. Diagnosis was based on case history and clinical examination conducted in the field. Surgical 
treatment of both congenital and acquired fistulae was performed, when dictated, using routine maneuvers reported in literature and textbooks.

All surgical procedures were performed under effect of xylazine hydrochloride as a tranquilizer in a dose rate of $0.17 \mathrm{mg} / \mathrm{kg} \mathrm{b.w}$. in cattle and buffaloes, $0.5-$ $0.10 \mathrm{mg} / \mathrm{kg}$ b.w. in sheep, $0.5 \mathrm{mg} / \mathrm{kg}$ b.w. in goats, 5 $\mathrm{mg} / \mathrm{kg}$ b.w. in horses and donkeys, $0.3 \mathrm{mg} / \mathrm{kg}$ in camels (xylaject, ADWIA pharma Egypt). 2\% lidocaine hydrochloride (Depocaine 2\% DEPIKY pharma, Egypt) was used as local analgesic solution. The surgical techniques used for each type of fistulae were as follow:

\section{1- Recto-vaginal fistulae:}

It is a tract connects the lumen of the rectum with lumen of the vagina ( $\mathrm{n}=58$ animals). The area of operation at the perineal region below the tail was prepared for asptic surgery. Local infiltration of the seat of operation was performed using $2 \%$ lignocaine $\mathrm{Hcl}$ then epidural anesthesia is performed.

First step of operation: A circular skin incision is performed at the anal depression and the skin disc was dissected and removed. After that the stump of the rectum was bluntly dissected all around and sutured by a number of interrupted stitches to the skin edges using non - absorbable suture material then the stump of the rectum was opened and faeces were evacuated.

Second step of operation: Is the resection of rectovaginal fistula. The skin between the rectum and vagina is incised horizontally and the incision is extended craniad to the site of fistula. The blunt dissection continued around the fistulous tract then the fistula is transversally severed and the ventral rectal wound is closed by interrupted Lembert sutures in a transverse manner while the dorsal vaginal wound is closed in a longitudinal manner. The dead space behind the transected fistula is closed by simple interrupted sutures then the skin is closed as usual.

\section{2- Urethral fistulae with hypospadia:}

It is a tract connects the caudal part of urethral fissure of hypospadia with the skin surface $(n=31$ animals).

Treatment regime includes 3 options (Table 1):

1) Option one: To leave the animal without any surgical interference by the request of owners.

2) Option two: Is the closure of the urethral fissure and keep the urethral orifice in its place.

3) Option three: Is the reconstruction of a new urethra from the urethral fissure.

Table 1: Number of animals used in different options used for treatment of urethral fistulae:

\begin{tabular}{cccccccc}
\hline $\mathbf{N}$ & Options & Cattle & Buffaloes & Sheep & Goats & Donkeys & Total \\
\hline $\mathbf{1}$ & Option one & 8 & 3 & 4 & 1 & 2 & 18 \\
\hline $\mathbf{2}$ & Option two & 2 & 2 & 3 & 1 & 1 & 9 \\
\hline $\mathbf{3}$ & Option three & 1 & 1 & 1 & -- & 1 & 4 \\
\hline & Total & 11 & 6 & 8 & 2 & 4 & $\mathbf{3 1}$ \\
\hline
\end{tabular}

Option 2 (Misk et al., 2013) was conducted under effect of local analgesia using local infiltration of $2 \%$ lidocaine. Dissection of the skin edges at both sides of the ventral fissure was performed separating the urethral wall from the skin. The urethral edges were sutured together by absorbable suture material then the skin edges were sutured with interrupted stitches using silk.

In option 3 the same steps were performed as option 2 with addition to application of a long polyethyline tube in the urethral groove before suturing the urethral wall to establish a canal. The tube is kept in place for 7-10 days to maintain the process of urination and to create a canal after its removal.

\section{3- Teat fistula:}

It is a tract connects the teat cistern with the skin surface of the teat $(n=14$ animals). Congenital teat fistulae were recorded in 11 animals and acquired teat fistulae were recorded in 3 animals (table 1).

Surgical treatment was performed according to the following steps:

a) Application of tranquilizers as mentioned before then ring block around the base of affected teat was performed using $5 \mathrm{ml}$ lignocaine $2 \%$ solution.b

b) The teat and the surrounding udder skin was prepared for aseptic surgery.

c) Elliptical skin incision is performed including the fistulous opening.

d) The incision was passed through all layers of the teat except the lying mucous membrane.

e) The tissues between the skin edges were removed.

f) Suturing was started including the inner fibrous layer, muscular layer and outer fibrous layer with absorbable suture material and eyeless needle in simple continuous manner. 
g) The skin and s/c tissues were sutured using simple interrupted stitches or interrupted mattress suture with fine silk.

h) Elastic teat badage was applied then milk tube is applied for milking until healing occurs by $1^{\text {st }}$ intention.

i) Follow up period extends for a one month.

\section{4- Salivary fistulae:}

It is a tract connects between the lumen of the Stenson's duct of the parotid salivary gland and the skin surface. The salivary fistula was recorded in 14 buffaloes as acquired fistula due to trauma to the face of the animal or due to injury of the duct during surgical incision of an abscess present at the course of parotid duct.

One technique for treatment was suggested after Misk (2008) for correction of salivary fistulae in buffaloes as follow:

a) A $7-10 \mathrm{~cm}$ polyethylene tube was prepared as stent for parotid duct reconstruction.

b) The area of fistulous opening is prepared for aseptic surgery.

c) The stent is introduced into the duct in both directions and secured in place.

d) The fistulous opening was closed over the stint with silk suture.

\section{5- Oral fistulae.}

Oral fistula is a tract connects between the oral cavity and the skin surface of the face. It is recorded in 9 animals. The first group consists of 6 animals (cattle $=1$, buffaloes $=2$, sheep $=2$ and goats $=1$ ) were treated as fistulae in general. While the second group (donkeys $=3$ ) was corrected by cleaning of cheek wound and then prepared surgically for healing by second intention.

\section{6- Perianal fistulae:}

Perianal fistula is a tract connects between the lumen of the caudal part of the rectum and perianal skin. It is recorded in 3 animals (cattle $=1$, buffalo $=1$ and horse $=1$ ). Chemical cauterization was used 2-3 times at intervals of 3 days for treatment of 2 cases of cattle and buffalo while surgical excision was performed to treat the case of horse aiming for healing of the created wound by second intention.

The treatment outcomes for different fistulae were recorded and further recommendations were suggested.

\section{RESULTS}

6 types of congenital and acquired fistulae were recorded in the present study. The total number of affected animals is 129 (table 2). The fistulae include; recto-vaginal fistulae $(\mathrm{n}=58)$, urethral fistulae with hypospadia $(\mathrm{n}=31)$, teat fistulae $(\mathrm{n}=$ $14)$, salivary fistulae $(n=14)$, oral fistulae $(n=9)$ and perianal fistulae $(n=3)$.

Congenital fistulae (C) affected 94 animals include recto-vaginal, urethral and teat fistulae while acquired fistulae (A) affected 35 animals and include recto-vaginal, teat, salivary, oral and perianal (table 3). Female animals were 91 while male animals were 38 (table 4).

Table 2: Showing types of fistulae and the number of affected animals.

\begin{tabular}{|c|c|c|c|c|c|c|c|c|c|c|c|c|c|c|c|}
\hline \multirow{2}{*}{ Type of fistulae } & \multicolumn{2}{|c|}{ Cattle } & \multicolumn{2}{|c|}{ Buffaloes } & \multicolumn{2}{|c|}{ Sheep } & \multicolumn{2}{|c|}{ Goats } & \multicolumn{2}{|c|}{ Camels } & \multicolumn{2}{|c|}{ Donkeys } & \multicolumn{2}{|c|}{ Horses } & \multirow{2}{*}{ Total } \\
\hline & $\mathrm{C}$ & A & $\mathrm{C}$ & A & $\mathrm{C}$ & A & $\mathrm{C}$ & A & $\mathrm{C}$ & A & $\mathrm{C}$ & A & $\mathrm{C}$ & A & \\
\hline Recto-vaginal & 21 & 1 & 9 & 1 & 10 & -- & 8 & -- & 2 & -- & -- & -- & -- & 6 & 58 \\
\hline Urethral & 11 & -- & 6 & -- & 8 & -- & 2 & -- & -- & -- & 4 & -- & -- & -- & 31 \\
\hline Teat & 7 & 1 & 4 & 1 & -- & -- & -- & -- & -- & 1 & -- & -- & -- & -- & 14 \\
\hline Salivary & -- & -- & -- & 14 & -- & -- & -- & -- & -- & -- & -- & -- & -- & -- & 14 \\
\hline Oral & -- & 1 & -- & 2 & -- & 2 & -- & 1 & -- & -- & -- & 3 & -- & -- & 9 \\
\hline Perianal & -- & 1 & -- & 1 & -- & -- & -- & -- & -- & -- & -- & -- & -- & 1 & 3 \\
\hline Total & 39 & 4 & 19 & 19 & 18 & 2 & 10 & 1 & 2 & 1 & 4 & 3 & -- & 7 & 129 \\
\hline
\end{tabular}


Table 3: Number of different types of congenital and acquired fistulae recorded in the present study.

\begin{tabular}{lcccc}
\hline & Type of fistulae & Congenital & Acquired & Total \\
\hline Recto-vaginal & 52 & 6 & $\mathbf{5 8}$ \\
\hline Urethral & 31 & -- & $\mathbf{3 1}$ \\
\hline Teat & & 11 & 3 & $\mathbf{1 4}$ \\
\hline Salivary & & -- & 14 & $\mathbf{1 4}$ \\
\hline Oral & Total & -- & 9 & $\mathbf{9}$ \\
\hline Perianal & $\boldsymbol{\%}$ & -- & 3 & $\mathbf{3}$ \\
\hline & $\mathbf{9 4}$ & $\mathbf{3 5}$ & $\mathbf{1 2 9}$ \\
\hline
\end{tabular}

Table 4: Sex of affected animals in different types of fistulae.

\begin{tabular}{|c|c|c|c|}
\hline Type of fistulae & Female & Male & Total \\
\hline Recto-vaginal & 58 & -- & 58 \\
\hline Urethral & -- & 31 & 31 \\
\hline Teat & 14 & -- & 14 \\
\hline Salivary & 14 & -- & 14 \\
\hline Oral & 5 & 4 & 9 \\
\hline Perianal & -- & 3 & 3 \\
\hline Total & 91 & 38 & 129 \\
\hline$\%$ & 70.5 & 29.5 & $100 \%$ \\
\hline
\end{tabular}

1- Recto-vaginal fistulae $(n=58)$ were recorded mainly as a congenital fistulae $(\mathrm{n}=50)$ and sporadically as acquired $(n=8)$. It is a tract connects between the ventrum of the rectum and the dorsum of the vagina.

All cases of congenital recto-vaginal fistulae were accompanied by atresia ani and recorded from first days after parturition to two years old. Animals affected were cattle $(n=21)$, buffaloes $(n=9)$, sheep $(n=10)$, goats $(n=8)$ and camels $(n=2)$. The only observed clinical sign was the discharges of faeces from the vulva of animal. Presence of tail especially in sheep usually obscure such sign completely.

Acquired fistulae $(\mathrm{n}=8)$ were recorded in horses ( $\mathrm{n}$ $=6)$, cattle $(n=1)$ and buffaloes $(n=1)$. They occur as a result of complications of surgical treatment of perineal lacerations which were a sequellae occur during parturition. The successful rate of operations was mentioned in table $5 \mathrm{~A}$ and $\mathrm{B}$.

Table 5 A: Showing the successful rate of operations in animals affected with congenital recto-vaginal fistulae

\begin{tabular}{lccc}
\hline \hline Animals & $1^{\text {st }}$ Trial & $2^{\text {nd }}$ Trial & Total \\
\hline Cattle & 19 & 2 & 21 \\
\hline Buffalo & 8 & 1 & 9 \\
\hline Sheep & 9 & 1 & 10 \\
\hline Goats & $\mathbf{6}$ & 2 & 8 \\
\hline Camels & 2 & -- & 2 \\
\hline \multicolumn{1}{r}{ Total } & 44 & 6 & 50 \\
\hline \multicolumn{1}{r}{$\%$} & 88 & 12 & 100 \\
\hline
\end{tabular}

Table 5 B: Showing the successful rate of operations in animals affected with acquired recto-vaginal fistulae

\begin{tabular}{|l|c|c|c|}
\hline Animals & $1^{\text {st }}$ Trial & $2^{\text {nd }}$ Trial & Total \\
\hline Horses & 4 & 2 & 6 \\
\hline Cattle & 1 & -- & 1 \\
\hline Buffalo & 1 & -- & 8 \\
\hline Total & 6 & 2 & 100 \\
\hline$\%$ & 75 & 25 & \\
\hline
\end{tabular}




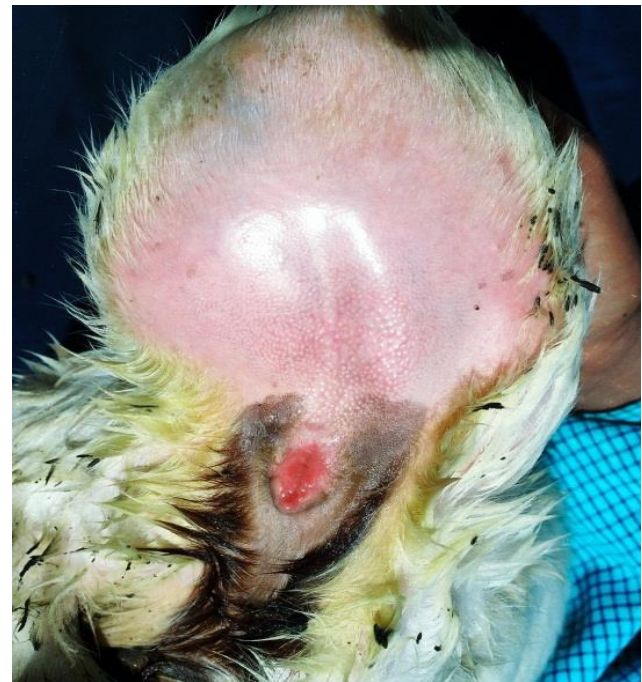

Fig. 1: Rectovaginal fistula with atresia ani in a sheep.

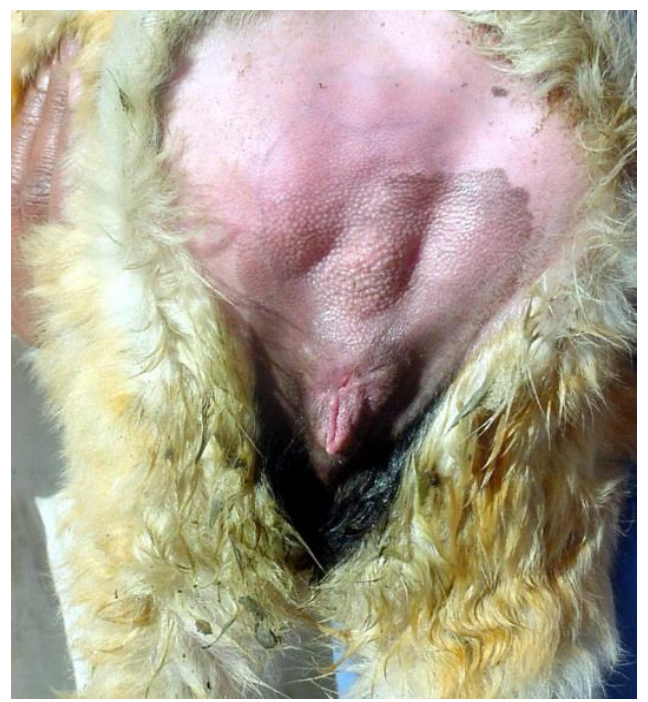

Fig. 2: Rectovaginal fistula with atresia ani in a

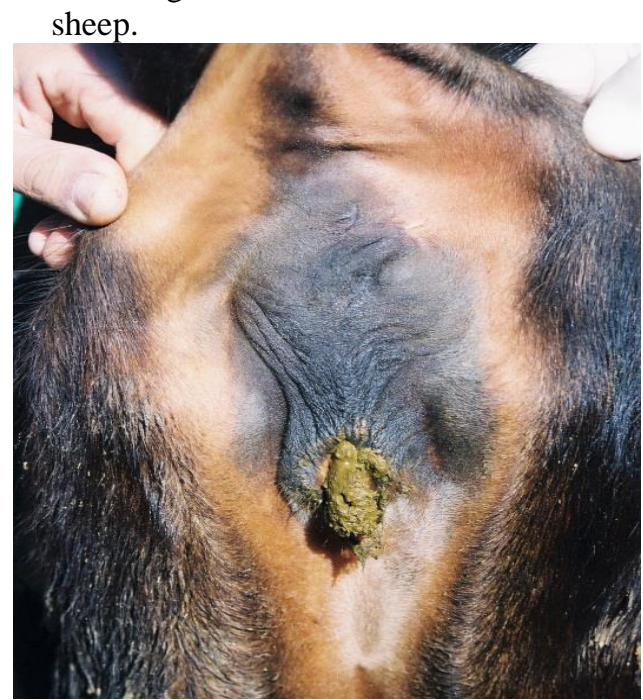

Fig. 3: Rectovaginal fistula with atresia ani in a calf.

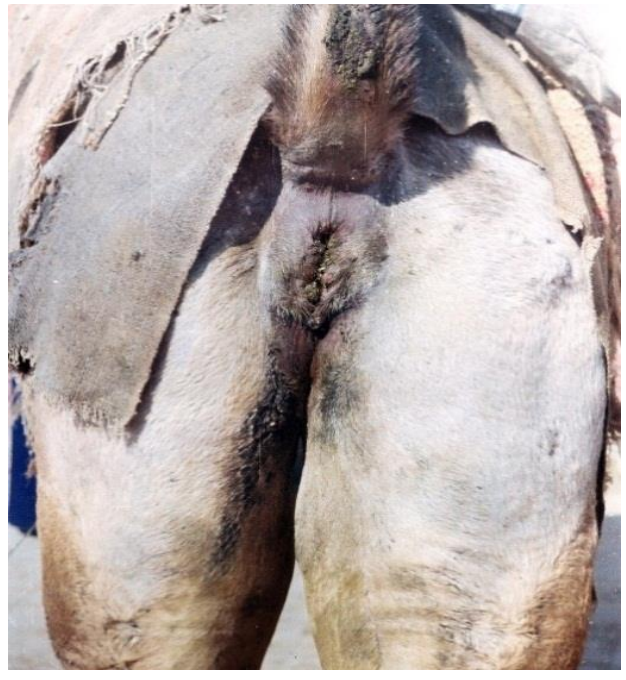

Fig. 4: Rectovaginal fistula with atresia ani in a camel.

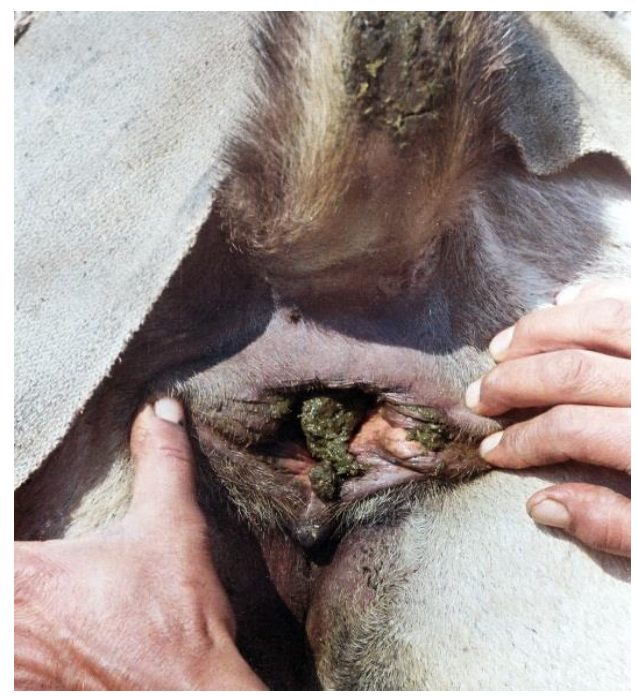

Fig. 5: Close Up of fig.

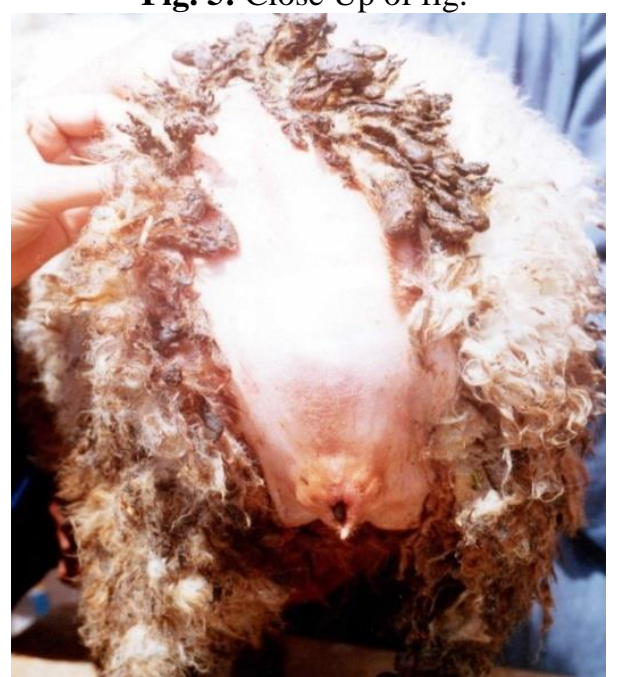

Fig. 6: Atresia ani and recto-vaginal fistula in a ewe. 


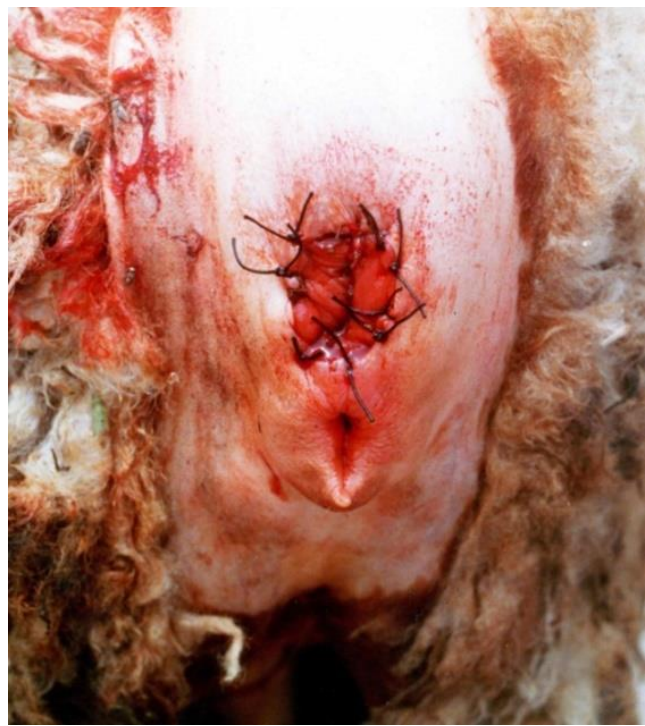

Fig.7: The same case in Fig.6. after reconstruction of anal opening.

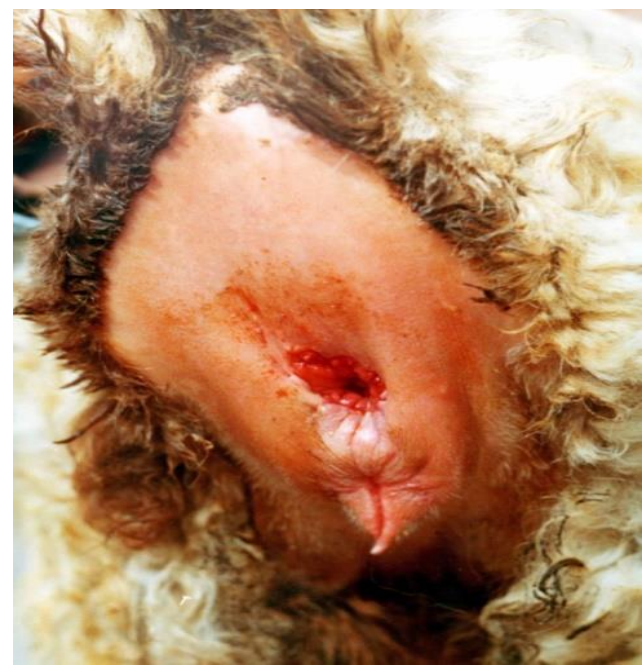

Fig.8: The same case in Fig.6. two weeks after operation.

\section{2- Urethral fistula:}

31 Urethral fistulae were recorded in the present study accompanied by hypospadia in male animals; cattle $(n=11)$, buffaloes $(n=6)$, sheep $(n=8)$, goats $(n=2)$ and donkeys $(n=4)$. Hypospadias were present in animals from the time of birth but discovered by the owners after a long period of time extends up to two years. In most cases the passage of urine is intact from a caudal urethral orifice. The

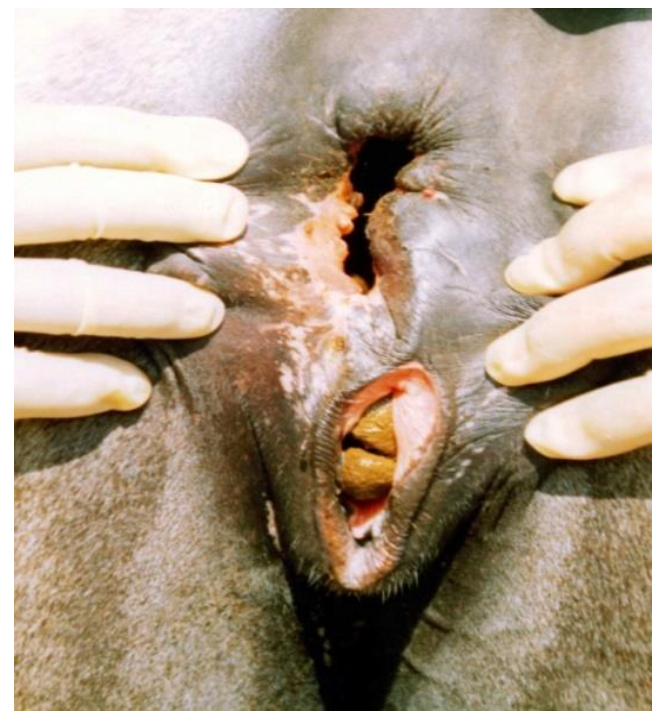

Fig.9: An old case of third degree of perineal laceration transformed into recto-vaginal fistula in a mare.

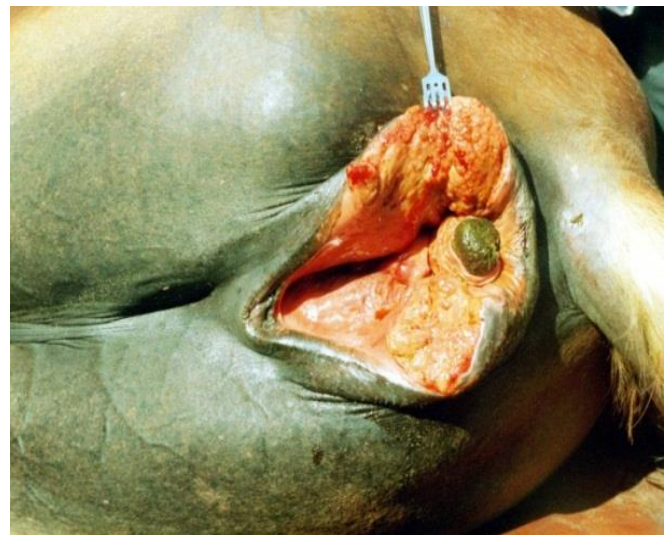

Fig.10: An old case of third degree of perineal laceration with recto-vaginal fistula in a mare.

urethral fissure is exposed all time for irritation and trauma. The hypospadia may include the whole length of penile urethra from the level of ischial arch caudally to the glans penis cranially (total hypospadia) or restricted to a part of the urethra and known as balanitic, penile, scrotal and perineal. The urethral orifice is present at the caudal end of urethral fissure. The following table illustrates different types of hypospadia in the present study.

\begin{tabular}{lccc}
\hline Hypospadia & Total h. & Penile h. & Total \\
\hline Animals & 9 & 2 & 11 \\
\hline Buffle & 4 & 2 & 6 \\
\hline Sheep & 6 & 2 & 8 \\
\hline Goats & $\mathbf{1}$ & 1 & 2 \\
\hline Donkeys & 4 & -- & 4 \\
\hline Total & 24 & 7 & 31 \\
\hline$\%$ & 77.4 & 22.6 & $100 \%$ \\
\hline
\end{tabular}


The results indicated that option 2 is better than option 3. The selection of option one depends upon the request of owners. All cases operated in option 2 were recovered without any postoperative

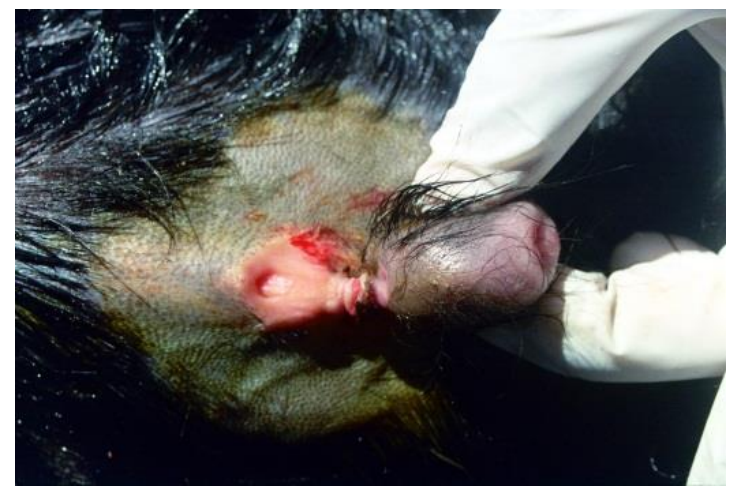

Fig. 11: Urethral fistula due to penile hypospadia in a kid.

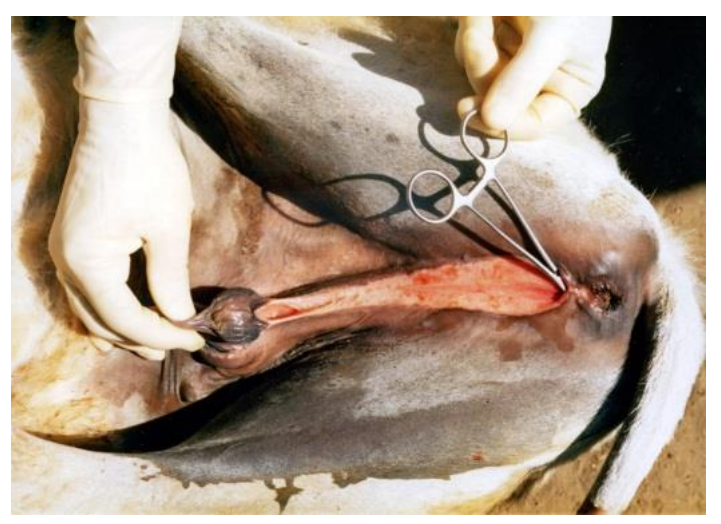

Fig. 12: Urethral fistula due to total hypospadia in a donkey.

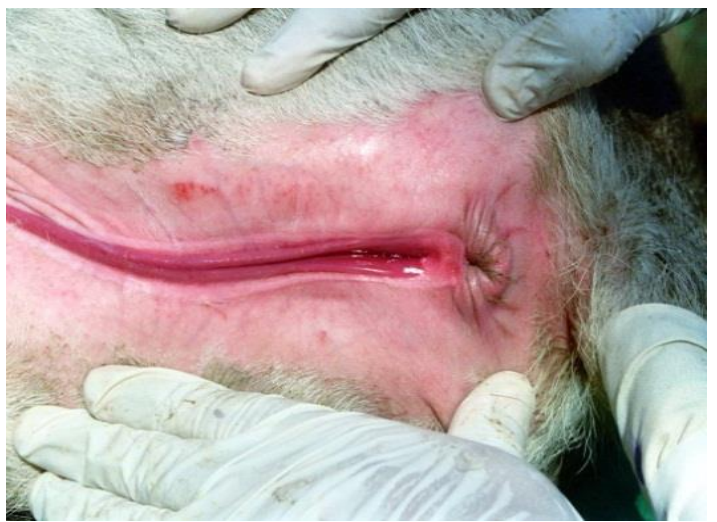

Fig. 13: Urethral fistula due to perineal hypospadia in a calf.

\section{3- Teat fistula:}

It is a tract connects the teat cistern and the skin surface of the teat. 14 teat fistulae were recorded in the present study in cattle $(n=8)$, buffaloes $(n=5)$ and camels $(\mathrm{n}=1)$. Congenital teat fistulae were recorded in 11 animals and acquired teat fistulae in 3 animals. The congenital teat fistulae were recorded at time of first lactation while acquired teat fistulae were registered as a complication of teat laceration complications while in option three, 2 out of 4 operated animals a new urethral canal was established and the urethral orifice is moved cranially just behind the glans penis.

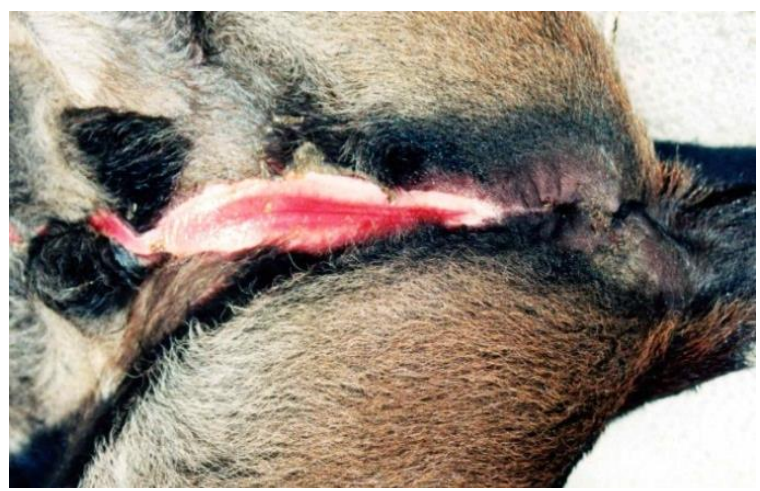

Fig.14: Hypospadia in a kid (balanitic, penile, and scrotal forms).

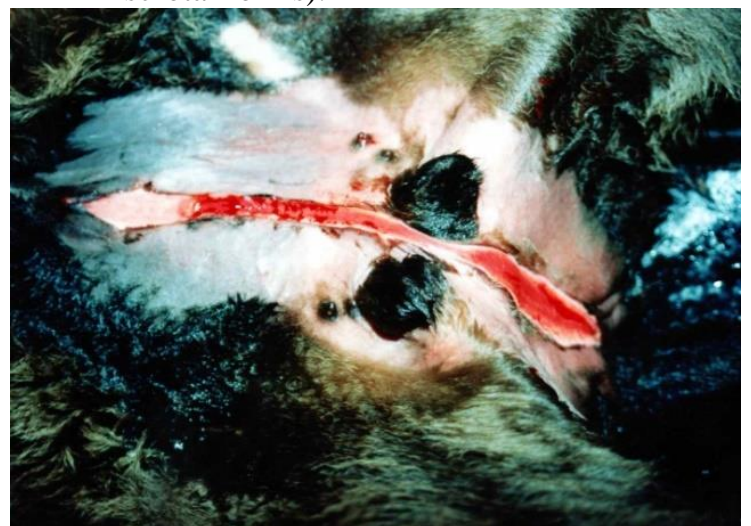

Fig.15: Hypospadia in a kid (balanitic, penile, scrotal, and perineal forms)

on 4-10 days following trauma. An udder fistula is recorded in a one camel.

Surgical treatment was performed to all cases and the results of operation revealed healing by first intention within 7-10 days in 12 cases and recurrences in two cases and surgery was repeated 15 days later with satisfactory results. 


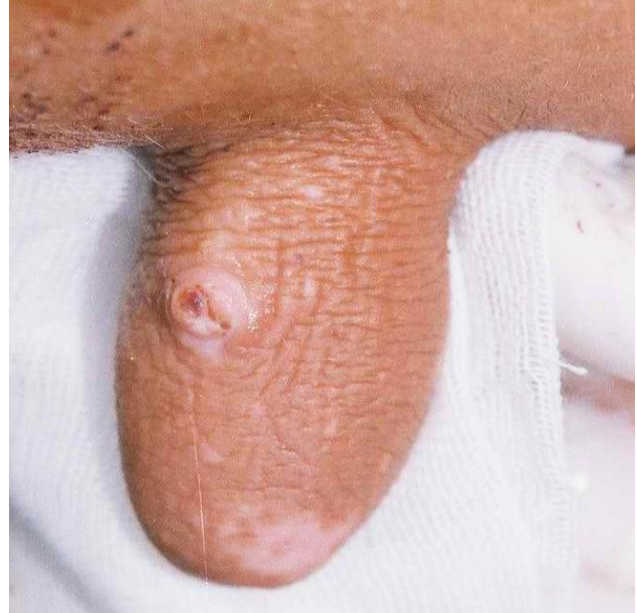

Fig.16: Teat fistula in a cow.

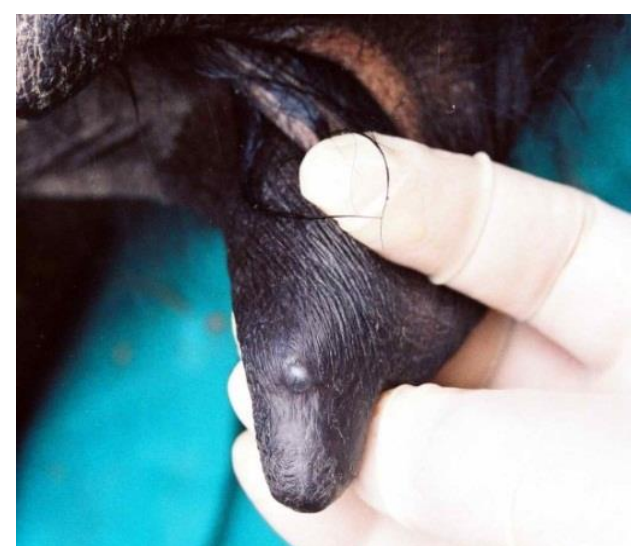

Fig.17: Teat fistula in a cow.

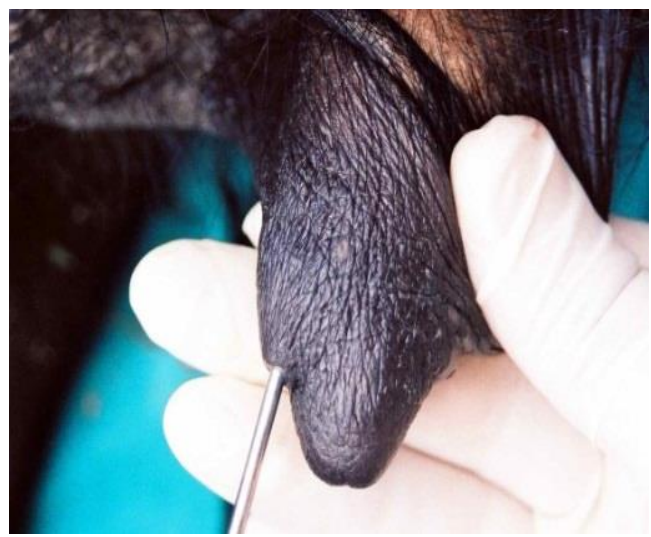

Fig.18: Propping of a teat fistula of case in Fig. 17.

\section{4- Salivary fistula:}

It is a tract connects between the lumen of the Stenson's duct of the parotid salivary gland and the skin surface anywhere along the course of parotid duct. The salivary fistula was recorded in 14 buffaloes as acquired fistulae and occured due to trauma or abscess formation at the face of the animal. The fistula was observed first by the owner who stated that his animal has a free discharge of water secretion form an opening on the lower part of the jaw on one side of the head and the secretion is

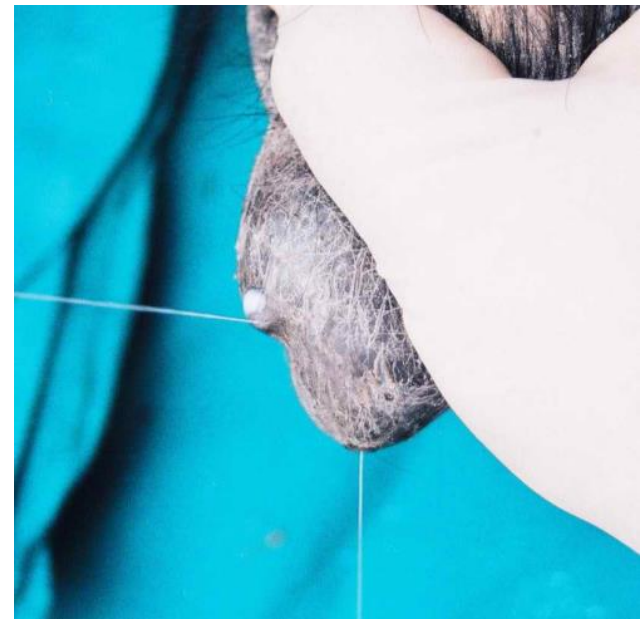

Fig.19: Teat fistula in a cow. Note both fistula and primary teat orifice discharge milk.

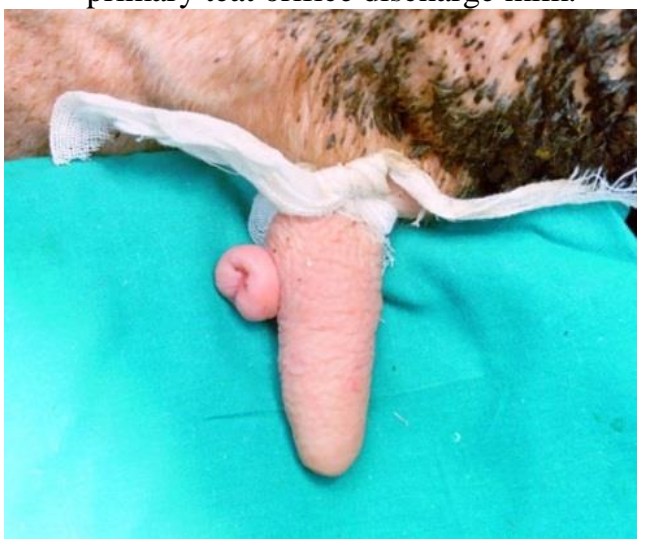

Fig. 20: Teat fistula with presence of abnormal overgrowth around the fistual orifice in a cow.

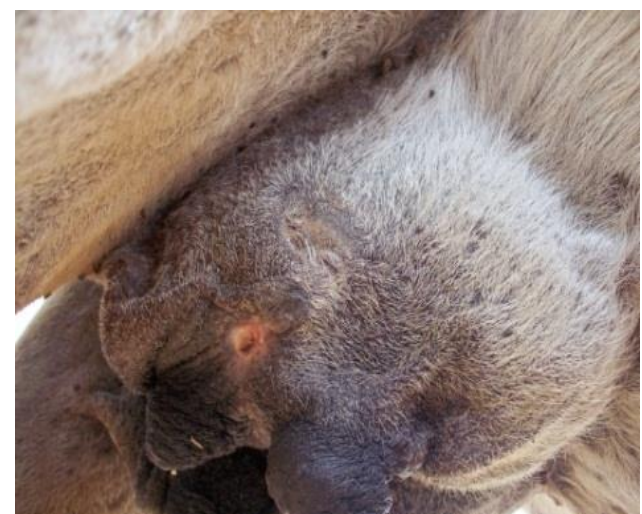

Fig. 21: Udder fistula in a camel.

increased at time of feeding. Examination using a metal probe revealed presence of a patent duct in both directions.

Partial reconstruction of the Stenson's duct suggested by the author of the present study using a $10 \mathrm{~cm}$ piece of polyethylene tube was performed in all cases (Misk 2008). The results of operation and follow up were registered for one month postoperatvely. 
Results revealed complete recovery of 12 cases. In two cases the stent was moved toward the mouth cavity and expose the fistulous opening. The stent is changed and applied for the second time.

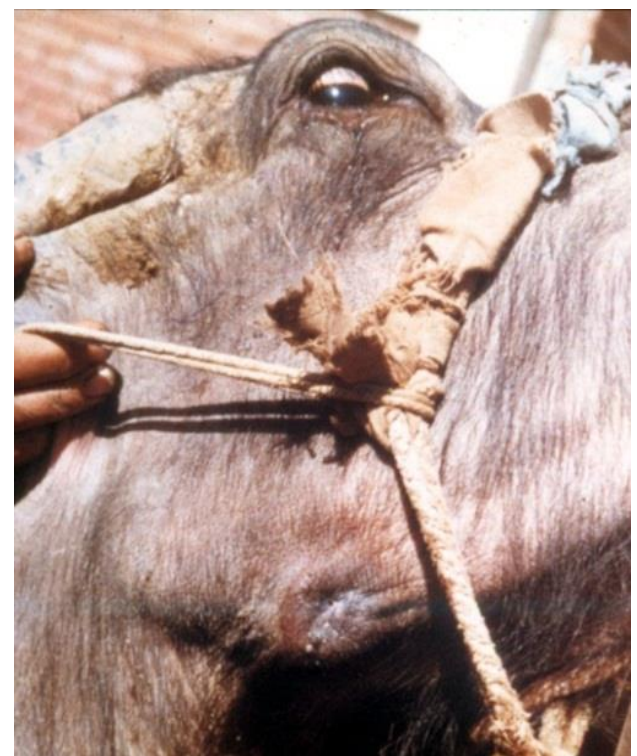

Fig.22: Salivary fistula of the parotid duct in a buffalo.

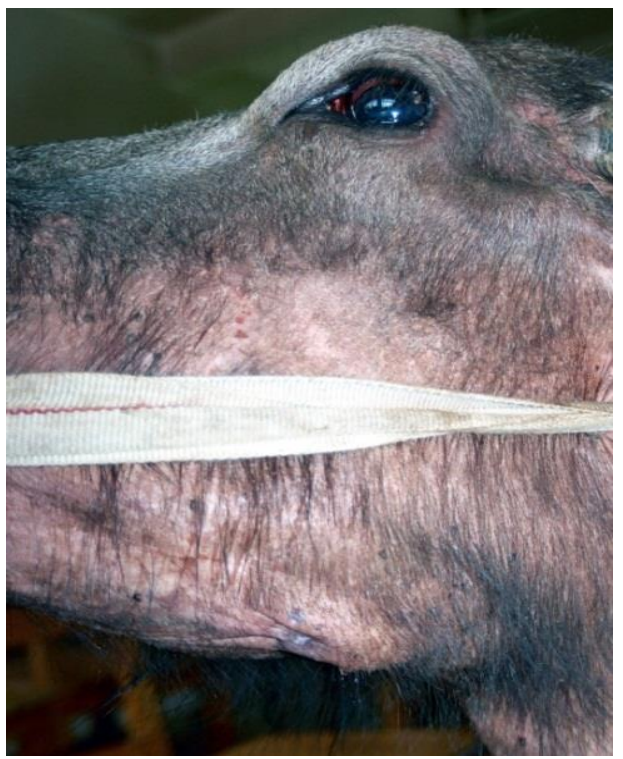

Fig. 23: Salivary fistula of the parotid duct in a buffalo.

\section{5- Oral fistulae:}

It is a tract connects between the oral cavity and the skin surface of the face mostly at the level of cheek and mandible ( $\mathrm{n}=9$ animals). Oral fistula is an acquired condition observed in cattle $(n=1)$, buffaloes $(n=2)$, sheep $(n=2)$, goats $(n=1)$ and donkeys $(n=3)$. Periodontal disease was responsible for occurrence of the condition in ruminants while motor car accident was the cause in donkeys.

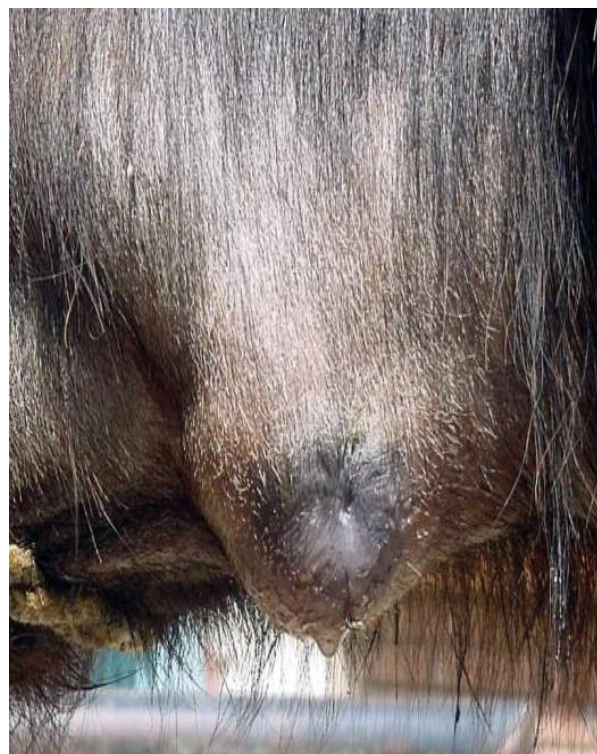

Fig. 24: Salivary fistula of the parotid duct in a buffalo. Note the dropping of saliva from the fistulous orifice.
Exfoliation of one of the cheek teeth due to periodontal disease leads to formation of dental sinus with subsequent formation of an oral fistula discharging ingesta mixed with saliva. Accidents in donkeys lead to a lacerating wound which transformed into oral fistula due to neglection of treatment. The result of treatment of both types of oral fistulae was satisfactory and occurs in all cases without any postoperative complications. 


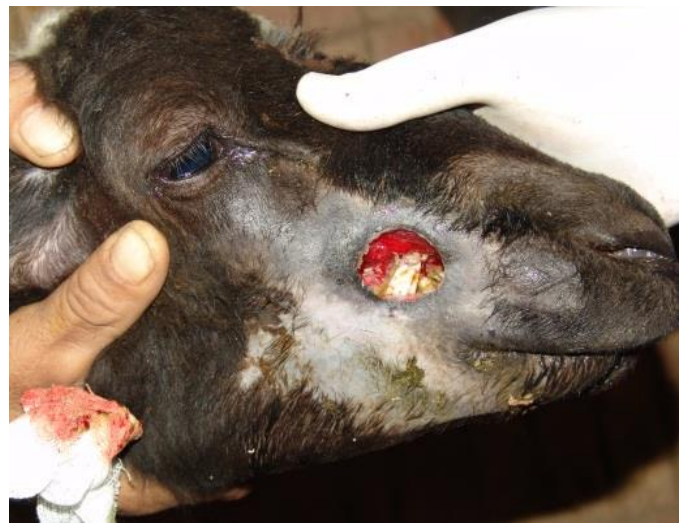

Fig.25: Oral fistula in a sheep.

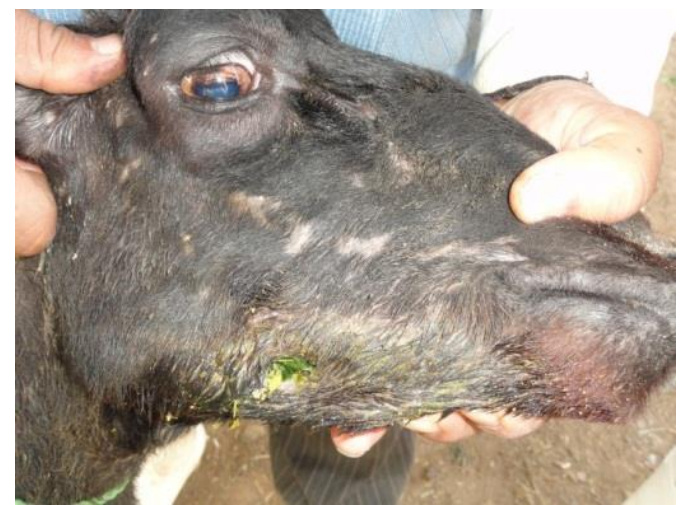

Fig. 26: Oral fistula in a sheep.

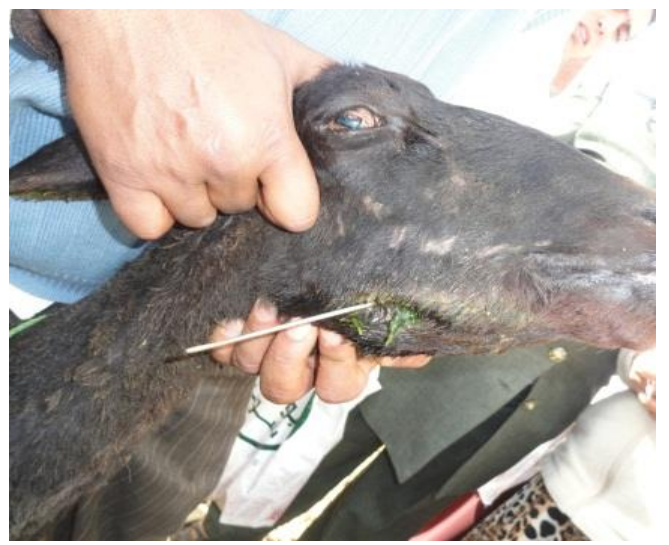

Fig. 27: Probing of the fistula indicates its connection with the oral cavity.

\section{6- Perianal fistulae:}

It is a tract connects between the lumen of the rectum and perianal skin. The condition was recorded sporadically in 3 animals; cattle $(n=1)$, buffalo $(\mathrm{n}=1)$ and horses $(\mathrm{n}=1)$. A probe introduced into the perianal opening leads directly to the rectum. Ingesta mixed with purulent exudate was seen discharging from the fistulous opening.

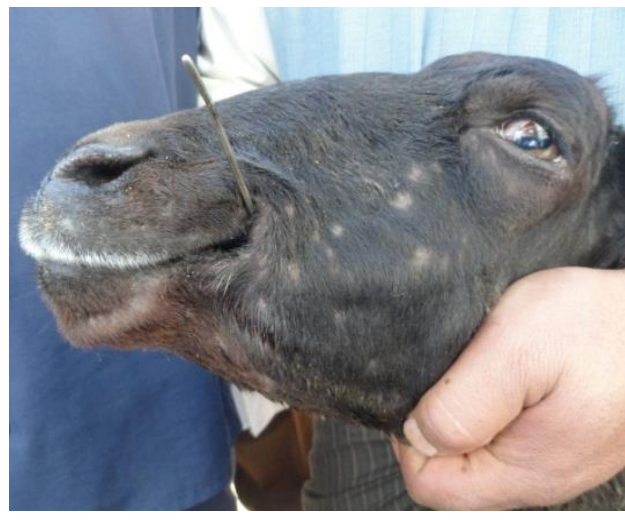

Fig. 28: Probing of fistula indicates its connection with the oral cavity.

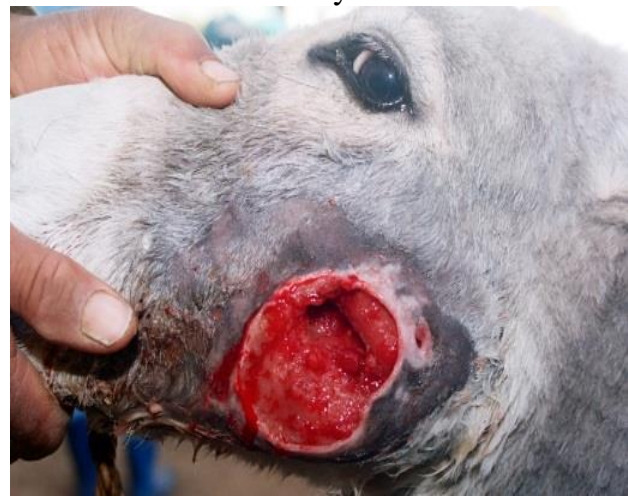

Fig. 29: Oral fistula due to lacerating wound in a

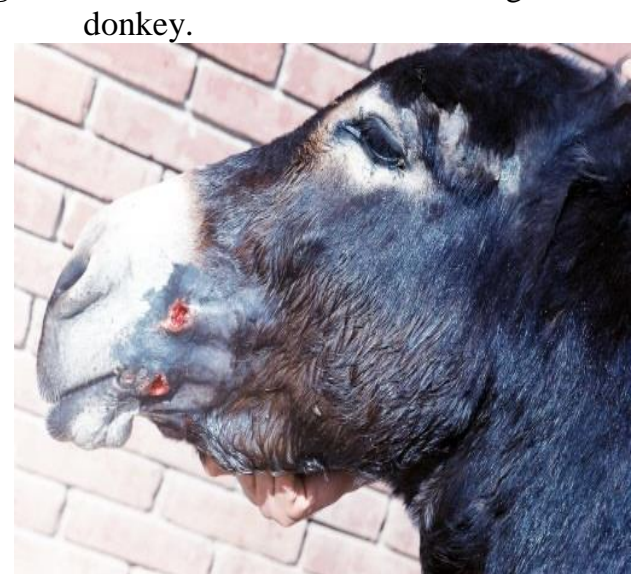

Fig.30: Oral fistula due to punctured wound in a donkey.

Chemical cauterization was used to treat cases of perianal fistulae in cattle and buffalo with satisfactory results and surgical excision was performed for treatment the case in horse with late healing by second intention. 


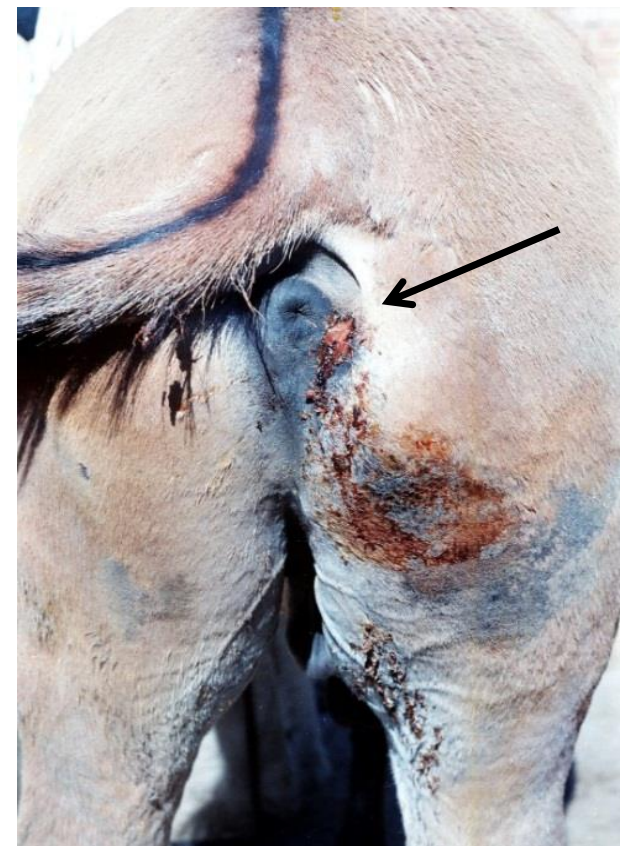

Fig. 31: Peri-anal fistula in a horse.

\section{DISCUSSION}

In spite of presence of more than 12 types of congenital and acquired fistulae registered in the available literatures, only 6 types were diagnosed in the present study during a considerable long period of time extended from 2003 to 2018 (Dyne et al., 1964; Ellison, 1995; Michael, 1995; Smith, 2001; Zopa et al., 2008; Misk et al., 2013; Shannon et al., 2013; Misk et al., 2014; Singh et al., 2016; Ogawa et al., 2017; Perego et al., 2017; Khan et al., 2018; Misk et al., 2018; Sato et al., 2019 and Yi Gao, 2019).

Causes may be attributed to the carelessness of owners and farmers to present their cases to the veterinarians and less dangerous effect of these fistulae to threaten the life of animals. Also the policy of owners for culling the affected animals by slaughtering or euthanasia decreases the chance to register different types of fistulae. Among the recorded fistulae only recto-vaginal, urethral, teat, salivary, oral and perianal fistulae were registered in the present study in some farm animals. The effect of these fistulae sometimes leads to perinatal mortality and may decrease the productivity and value of the animal (Ghanem et al., 2004; Ghanem et al., 2005; Bademkirin et al., 2006; Magda et al., 2007 and Bademkirin et al., 2009). Recto-vaginal fistulae with atrasia ani may lead to vaginitis and metritis which may decrease the chances of pregnancy. Surgical intervention of such cases is the only possible solution to satisfy the sentiments of owners and to make them economically profitable for the keepers (Shakoor et al., 2015 and Phaneendra et al., 2015).

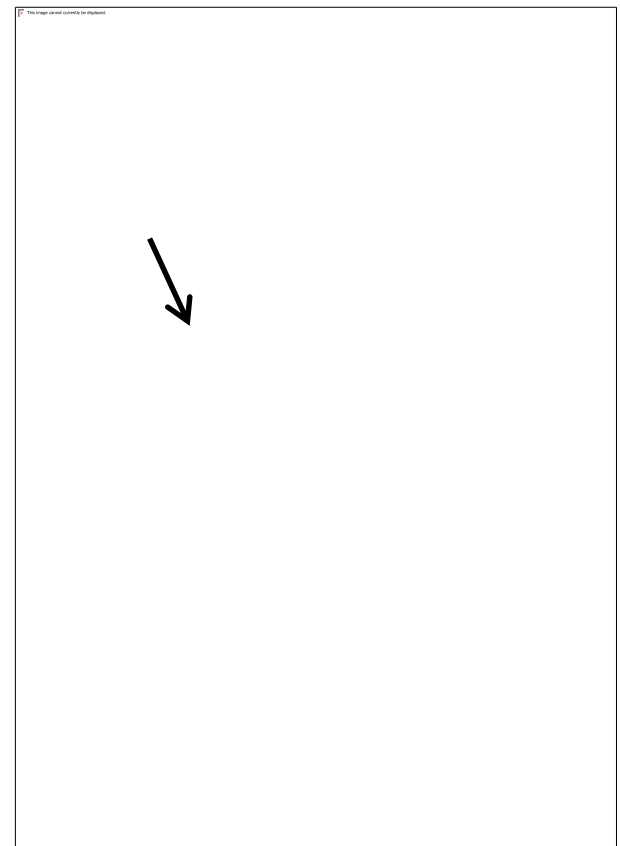

Fig. 32: Peri-anal fistula in a cow.

The most common registered fistulae in our present study was congenital recto-vaginal fistulae with atresia ani (50 animal out of 58). The rest of rectovaginal fistulae were acquired and seen in 6 mares suffering from complications of treatment of $3^{\text {rd }}$ degree of perineal lacerations in addition to one cattle and one buffalo suffering from perforation of the dorsum of the vagina and ventrum of rectum during parturition. The successful rate of surgical treatment of recto-vaginal fistula with atresia ani was high in the present work (45 animals out of 50) as the treatment is simply limited to reconstruction of the anal opening and resection and closure of the recto-vaginal fistulae in one or two steps operation with few days interval (Bademkiran et al., 2009; Shakoor et al., 2015 and Phaneendra et al., 2015). Two cases only needs widening of the anal opening few days after operation. Cases of recto-vaginal fistulae occur due to complications of perineal laceration in mares were managed by the same technique mentioned in this study with successful results.

Urethral fistulae were recorded in 31 animals. All cases were congenital and accompanied by hypospadia. The latter is a presence of urethral fissure along or partially along the ventral aspect of the penile urethra and extends for a different distance thus balanitic, penile, scrotal and perineal hypospadias were given to explain such condition. In all cases caudal urethral openings were patent and keep the process of urination intact and thus the owners complain was restricted to the presence of a bared red line of the urethral mucosa at the ventral aspect of the caudal abdomen which irritate the owners more than the animal itself. 
The proposed suggested technique in option two for treatment of urethral fistulae in the present study was accepted by owners as the aim of this option is to cover the exposed mucosa. Complete reconstruction of the penile urethra in option 3 is a long procedure and necessitates frequent observation and management with less satisfactory results than option 2. Neglection of treatment is dangerous and expose the bared mucosa to inflammation and traumas and bad look for the ventral abdominal wall.

Teat fistulae were recorded in the present study as congenital $(\mathrm{n}=11)$ and acquired $(\mathrm{n}=3)$ fistulae in cattle $(n=8)$, buffaloes $(n=5)$ and camel $(n=1)$. It is an abnormal passage between the teat cistern and the teat surface through which the milk flows out in lactating animals (Aruljothi et al., 2012 and Misk et al., 2018). The surgical procedure mentioned in the present study was sufficient for treatment of both congenital and acquired fistulae. 12 cases were corrected from the first surgical interference while 2 cases only necessitate a second approach due to formation of another teat fistula.

Acquired salivary fistulae are mostly recorded in literatures affecting buffaloes (Ahmed, 1988; Misk et al., 1988; Semieka, 2002 and Misk, 2012) and the same happened in our present study in which 14 cases were recorded in buffaloes only. No one know up till now why in buffaloes only, the question which need answer from the researchers. The suggested technique by the author of this study still act as a good solution for treatment of salivary fistula in buffaloes (Misk, 2008 and Misk et al., 2014). Reconstruction of the parotid duct at the seat of fistula by a segment of polyethylene tube was satisfactory and better than all other suggested techniques.

Oral fistulae were recorded in 9 animals. All of them were acquired due to old cheek wounds occur in 4 animals after a motor car accident and 5 of them are due to untreated cases of periodontal disease in which exfoliation of the affected teeth open the way for dental sinuses to be converted into oral fistulae. The fistula discharges food materials mixed with saliva. In the available literatures oronasal fistulae were formed due to the same dental condition affecting the canine teeth in dog (Smith, 2001 and Ogawa et al., 2017). Treatment of such cases was time consuming because cases of oral fistula at the cheek region necessitate several measures to obtain healing by second intention and the same for cases due to dental sinuses which need thorough cleaning and thermal cauterization of the fistulous tract to obtain healing by second intention.

Acquired perianal fistulae were recorded sporadically in 3 cases. Medical treatment is a satisfactory solution for such cases because of the critical location of fistulae (Ellison, 1995 and
Mathews et al., 1997). Many authors suggest chemical cauterization of the tract, cryosurgery and surgical excision (Liska et al., 1975; Vasseur, 1984 and Mathews et al., 1997).

In conclusion surgical intervention is the only possible solution to treat almost all registered congenital and acquired fistulae recorded in the present study to satisfy the requirements of the owners and to make the affected animals more profitable to the national income.

\section{REFERENCES}

Ahmed, IH. (1988): Surgical affection of the salivary glands in some domestic animals. Phd, Assiut university, Egypt

Aruljothi, N.; Balagopalan, TP.; Rameshkumar, B. and Alphonse, RMD. (2012): Teat fistula and its surgical management in bovines. Intas polivet. Voi.13(1) : 40-41.

Bademkiran, S.; Icen, H. and Kurt, D. (2009): Congenital recto vaginal fistula with atresia Ani in a heifer: A cases report. Y.Y.U. Veterinary Fakultesi Dergisi, 20(1) 61-64.

Bademkirin, S.; Kanay, EE. and Ozyurdu, N. (2006): Bir Dist Buzagida fissure abdo minnalis olgusu. vet cer derg, 12 (1-2-3-4), 33-35.

Dyne, GV. and Torell, DT. (1964): Development and use of esophageal fistula: A Review journal uair arisona edu. University of California, Davis, California.

Ellison, GW. (1995): Treatment of perianal fistula in dogs. Journal of American veterinary Meadical Association 1995, 206. 1680- 1682.

Ghanem, M.; Yoshida, C.; Isobe N. Nakaot; Yamashiro, H.; Kubota, H.; Miyake, Y. and Nakada, K. (2004): Atresia ani with diphallus and separate scrota in a calf. A cases report. Theriogenology 61, 1205-1213.

Ghanem, ME.; Yoshida, C.; Nishibori, M.; Nakao, T. and Yamashiro, H. (2005): A cases of free martin with atresia recti and ani in Japanese black calf Anim Reprod Sci, 85, 193-199.

Khan, S.; Satheesh, A.; Sabarinadh, VR.; Ranjith, MM.; Sidhique, SA. and Panikkassery, S. (2018): Surgical management of enterocutaneous fistula secondary to dog bite wound in a male bari goat. Journal of Entomology and zoology studies 6 (6): 927929.

Liska, WD.; Greiner, TP. and Withroe, SJ. (1975): Cryosurgery in the treatment of perianal fistulae Vet. Clin North Am Small Anim. Pract: 5.449-456.

Magda, MA. and Youssef, HA. (2007): Surgical management of congenital malformations in ruminants. Www.priory.com/ vet/ congenitalmalformation - ruminants. Htm.04.10.2008. 
Mathews, K.A.; Ayres, SA.; Tano, CA.; Riley, SM.; Sukhiani, HR. and Adams, C. (1997): Cuclosporin treatment of perianal fistulas in dogs: Can Vet J. 38 (1), 39- 4.

Michael, RD. (1995): Umbilical hernias, umbilical abscesses and Urethral fistulae: Surgical consideration. Veterinary clinics: Food animal practice. Vol.11, No1, PP137- 148.

Misk, NA. (2008): Atlas of veterinary surgery. Assiut university press, Assiut, Egypt

Misk, NA. (2012): Project entitled (Studies on early diagnosis of different abdominal disorders with special references to the surgical interference for treatment in cattle and buffaloes) Assiut University and ministry international cooperation, Egypt (2009-2012).

Misk, NA.; Hifny, A. and Ahmed, IH. (1988): Sialography of the Mandibular and Parotid Salivary Glands in Some Domestic Animals. Proceeding of 8th Meeting, International Veterinary Radiology Association, 21-26 August, Sydney - Australia.

Misk, NA.; Misk, TN.; EL-Khamary, A. and Semeika, M. (2018): A retrospective study of surgical affection of mammary glands in cattle and buffaloes and their management in the field. The journal of veterinary Medical science 80 (10): 1576- 1583.

Misk, NA.; Misk, TN. and Semeika, M. (2013): Diagnosis and treatment of affection of the urethra in male ruminants: A review of 403 cases. International journal of veterinary Medical: Research and Reports, vol.2013. Doi: 10.5171/ 2013. 715907.

Misk, NA.; Misk, TN.; Semieka, MA. and Ahmed, $A F$. (2014): Affections of the salivary ducts in buffaloes. Open veterinary Journal. Vol4 (1): 65-68.

Ogawa, M.; Yamaki, S.; Donari A. Wada and Hachimura, H. (2017): A retrospective study on 56 dogs with oronasal fistulas associated with periodontal disease.

Perego, R.; Spade, E.; Baggian, L.; Moneta, E. and Prowrbio, D. (2017): Clinical efficacy of autologous platelet - rich plasma (PRP) in treatment of perianal fistulas in a German shepherd dog. Italian Journal of companion practice 3, PP 29-33.
Phaneendra Mssv; Lakshmi, ND.; Kumar, KM. and Reddy, KS. (2015): Surgical management of congenital atresia ani (Imperforate anus) leadiug to recto- vaginal fistula in a cow calf. International $\mathrm{J}$. of science environment and technology, vol.4 (1110-1113).

Sato, R.; Kamimura, N. and Kaneko, K. (2019): Surgical repair of third degree perineal laceration with rectovestibular fistulae in dairy cattle: A series of four cases (20102018), Journal of Veterinary Meadical Science vol. (2019) No.5 PP703-706.

Semieka, MA. (2002): Parotid duct affections in some domestic animals. Assiut Vet. Med.J. 47,312-324.

Shakoor, A.; Muhammad, S.; Younus, M. and Kashif, M. (2011): Surgical repair of congenital recto-vaginal fistula with atresia ani in a cow calf. Pak Vet J, 32(2) 298-300.

Shannon, J.; Murray, J.; Yvonne, AE.; Woodie, JB.;Embertson, RM.; Roberton, JT. and Beard, WL. (2013): Evaluation of survival rate and athletic ability after nonsurgical or surgical treatment of cleft palate in horses: 55 cases (1986-2008). Journal of the American Veterinary Medical Association. Vol.243, No.3, PP406-410.

Singh, S.; Palecha, S.; Jhirwal, SK. and Bishnoi, P. (2016): Surgical management of ruminal fistula - a report of 2 heifers. Intas polivet Vol.17 No.1.

Smith, MM. (2000): Oronasal fistula repair clinical techniques in small animal practice. Vol. 15, Issue 4, PP 243- 250.

Smith, MM. (2001): Island of palatal mucoperiosteal flap for repair of oronasal fistula in a dog. Journal of Veterinary Dentistry.

Vasseur, PB. (1984): Results of surgical excision of perianal fistulas in dogs $\mathrm{J}$ Am vet med Assoc 185: 60-62.

Yi Gao; Rong- Qian Wu; Yi Ly and Xiao-Peng Yan (2019): Novel magnetic compression technique for establishment of a canine model of tracheoesophageal fistula. World veterinary of Gastroenterology 25(30): 42134221.

Zopa, AN.; Amle, MB. and Zambra, PC. (2008): Congenital recto-vaginal fistula and atresia ani Indian J. Vet. Res. vol. 17No.2 PP14-16.

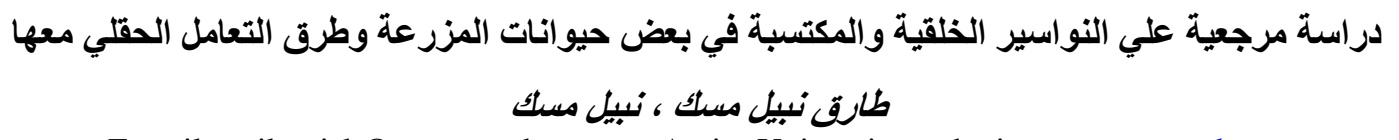

E-mail: tarik.misk@vet.usc.edu.eg Assiut University web-site: www.aun.edu.eg

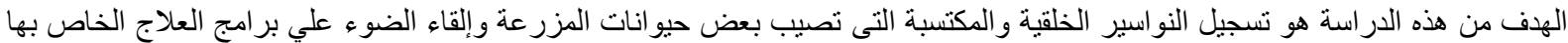

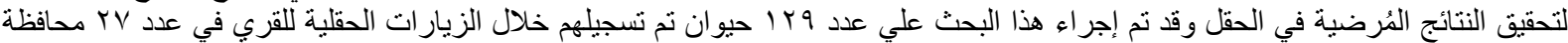

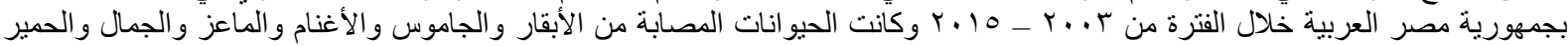

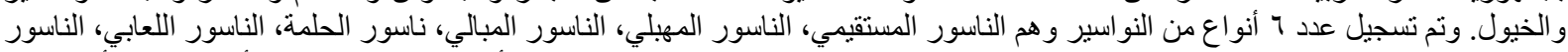

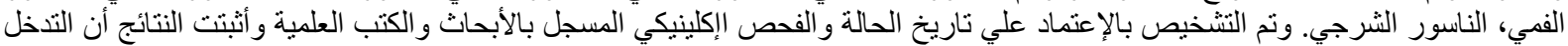

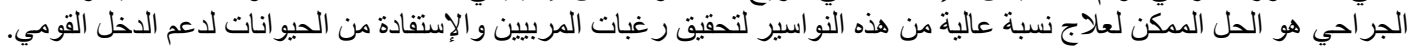

